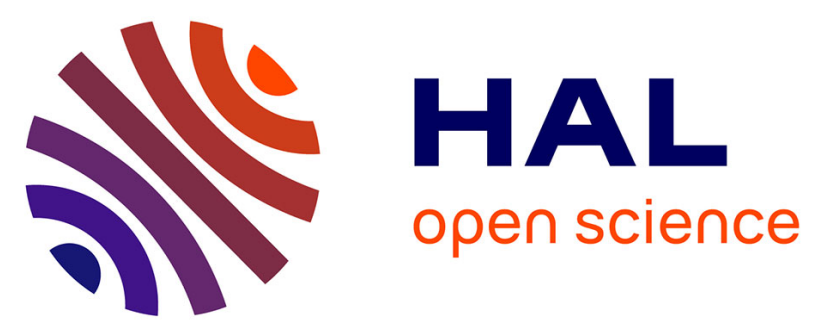

\title{
Control of an electropneumatic actuator: comparison between some linear and non-linear control laws
}

Xavier Brun, M. Belgharbi, Sylvie Sesmat, Daniel Thomasset, Serge Scavarda

\section{To cite this version:}

Xavier Brun, M. Belgharbi, Sylvie Sesmat, Daniel Thomasset, Serge Scavarda. Control of an electropneumatic actuator: comparison between some linear and non-linear control laws. Proceedings of the Institution of Mechanical Engineers, Part I: Journal of Systems and Control Engineering, 1999, 213 (5), pp.387-406. 10.1243/0959651991540232 . hal-00141155

\section{HAL Id: hal-00141155 \\ https://hal.science/hal-00141155}

Submitted on 1 Apr 2019

HAL is a multi-disciplinary open access archive for the deposit and dissemination of scientific research documents, whether they are published or not. The documents may come from teaching and research institutions in France or abroad, or from public or private research centers.
L'archive ouverte pluridisciplinaire HAL, est destinée au dépôt et à la diffusion de documents scientifiques de niveau recherche, publiés ou non, émanant des établissements d'enseignement et de recherche français ou étrangers, des laboratoires publics ou privés. 


\title{
Control of an electropneumatic actuator, comparison between some linear and nonlinear control laws.
}

\author{
X. BRUN, M. BELGHARBI, S. SESMAT, D. THOMASSET, S. SCAVARDA. \\ email: xavier.brun@1ai.insa-lyon.fr / mazouz.belgharbi@lai.insa-lyon.fr \\ Laboratoire d'Automatique Industrielle, Institut National des Sciences Appliquées de Lyon, Bâtiment 303, Villeurbanne, France.
}

\begin{abstract}
The aim of this paper is to present and to compare some linear and nonlinear control laws for an electropneumatic positioning system as well for point to point control as for tracking control. The experimental results are presented in terms of repeatability for each control law implemented on the same device: an in line electropneumatic servo-drive. Different kinds of models: nonlinear affine, linearised tangent and a reduced linearised tangent model are presented to synthesize the different control laws. For this a new mathematical modelling of the servo-distributor flow stage is described.
\end{abstract}

Keywords: Fluid Power, Pneumatics, Modelling, Control, Industrial application.

\section{NOTATION}

$b \quad$ critical pressure ratio $(b=0.528)$

$C_{p_{X} J}^{e}=-\left.\frac{\partial q_{J}}{\partial p_{X}}\right|_{e}$, partial derivative of the mass flow rate $q_{J}$ according to $p$ around equilibrium state $(\mathrm{kg} / \mathrm{s} / \mathrm{Pa})$

$f_{v} \quad$ viscous friction coefficient $(\mathrm{N} /(\mathrm{m} / \mathrm{s}))$

$F \quad$ force $(\mathrm{N})$

$G_{u J}^{e} \quad=\left.\frac{\partial q_{J}}{\partial u}\right|_{e}$, partial derivative of the mass flow rate $q_{J}$ according to $u$ around equilibrium state $(\mathrm{kg} / \mathrm{s} / \mathrm{V})$

$k \quad$ polytropic constant

$K_{y}, K_{v}, K_{a}$ position gain $(\mathrm{V} / \mathrm{m})$, velocity gain $(\mathrm{V} / \mathrm{m} / \mathrm{s})$ and acceleration gain $\left(\mathrm{V} / \mathrm{m} / \mathrm{s}^{2}\right)$

$M \quad$ total load mass $(\mathrm{kg})$

$p_{X} \quad$ pressure in the cylinder chamber $X(\mathrm{~Pa})$

$\mathrm{q}_{\mathrm{m}}$ mass flow rate provided from the servo-distributor to cylinder chamber $X(\mathrm{~kg} / \mathrm{s})$

$r \quad$ perfect gas constant related to unit mass $(\mathrm{J} / \mathrm{kg} / \mathrm{K})$

Re Reynolds number

$S_{X} \quad$ area of the piston cylinder on the chamber $X\left(\mathrm{~m}^{2}\right)$

$T \quad$ temperature $(\mathrm{K})$

$u \quad$ servo-distributor input voltage (V)

$V \quad$ volume $\left(\mathrm{m}^{3}\right)$

$x \quad$ state vector

$y, v, a, j$ position $(\mathrm{m})$, velocity $(\mathrm{m} / \mathrm{s})$, acceleration $\left(\mathrm{m} / \mathrm{s}^{2}\right)$, jerk $\left(\mathrm{m} / \mathrm{s}^{3}\right)$

$\underline{z} \quad$ reduced state vector $\varepsilon \quad$ absolute steady state position error

$\gamma \quad$ specific heat ratio

$\sigma \quad$ standard deviation $(\mathrm{mm})$

$\tau \quad$ time constant (s)

Subscript

c central position $\mathrm{V}_{\mathrm{P}}\left(\mathrm{y}_{\mathrm{c}}\right)=\mathrm{V}_{\mathrm{N}}\left(\mathrm{y}_{\mathrm{c}}\right)$

cl closed loop

d desired

$\mathrm{D}_{\mathrm{i}} \quad$ dead volume of chamber $\mathrm{i}$

down downstream

E exhaust

ext external

f dry friction

min minimum value

$\max$ maximum value

$\mathrm{N} \quad$ chamber $\mathrm{N}$

ol open loop

$\mathrm{P} \quad$ chamber $\mathrm{P}$

$r \quad$ reference

S supply

up upstream

$\mathrm{v} \quad$ viscous friction

0 initial value

Superscript

e equilibrium

Abbreviations

ADC Analog to Digital Conversion

DAC Digital to Analog Conversion

RACK Conditioning signal

Improv. Improvement 


\section{INTRODUCTION}

Due to low cost, clean working environments, easy for power transfer and good performance, pneumatic systems play an important role in industrial processes. During the last twenty years, the parallel development of pneumatic systems and control theory has lead to the implementation of modern control laws in pneumatic device (1).

The first control laws in Fluid Power concerned classical state feedback and were proposed by Shearer et al (2) and Burrows (3). The manufacturers of the first electropneumatic positioning systems such as Martonair (4) and GAS initially adopted it. Since then new sophisticated algorithms have been applied to electropneumatic systems: adaptive $(\mathbf{5}, \mathbf{6})$, sliding mode control $(\mathbf{7}, \mathbf{8}, \mathbf{9}), \mathrm{H}_{\infty}(\mathbf{1 0})$, fuzzy control (11), neural control (12)...

Nevertheless there are not many products present on the market. A possible reason may be that there are very few research papers comparing clearly classical linear control law with sophisticated nonlinear ones using the same equipment. This article shows the improvement obtained with two nonlinear control laws in pneumatic cylinder position control, for point to point and tracking operations.

After a description of the physical electropneumatic system on which the different control laws have been implemented, a mathematical model of the process is described. This means knowing the nonlinearities due to the compressibility of air, the friction force on the moving parts, the air mass flow rate through the servo-distributor, the pressure evolution in a chamber, etc... A tangent linearised model is presented and a new type of approximation for the servo-distributor mass flow rate leads to a nonlinear affine model used to synthesize a nonlinear control law.

All these control laws are elaborated in continuous time because the natural frequency of the electropneumatic system under study is very small in comparison to the sampling frequency used with digital signal processing (in ratio of 100).

We will try to answer the following question: "What improvements could the complex control
Journal of SYSTEMS AND CONTROL ENGINEERING Special Issue 'Controls in Fluid Power Systems" laws bring in electropneumatic fields?" For this, experimental results are presented in terms of repeatability: standard deviation, mean value, maximum error... and so a comparison between them is presented with appropriate benchmarking. All the tests have been carried out with the same pneumatic, electronic and computing system, this is very important to prove what kind of control law should be chosen for a certain aim.

\section{DESCRIPTION OF THE ELECTROPNEUMATIC SYSTEM}

The system under consideration (figure 1) is an in line electropneumatic servo-drive, using a simple rod $(32 / 20 \mathrm{~mm}$, which mean that the cylinder diameter is equal to $32 \mathrm{~mm}$, and rod diameter to 20 $\mathrm{mm}$ ) double acting linear pneumatic cylinder with a stroke of $500 \mathrm{~mm}$. Two three-way proportional Servotronic servo-distributors (Asco-Joucomatic Company) modulate the mass flow rates into the cylinder chambers. They consist of a spool sliding in a sleeve, actuated directly by a proportional solenoid acting against a spring. A state feedback position control of the spool is used in order to decrease the effects of hysteresis and to increase the bandwidth of the servo-distributor. For modelling, the two servo-distributors are considered as identical. The rod of the actuator is connected to one side of the carriage and drives an inertial load on guide rails. The total mass (piston, rod and carriage) is $17 \mathrm{~kg}$.

A pressure sensor is implemented on each cylinder chamber. The position is given by an external potentiometer, velocity is obtained by analog derivation.

The measurements are downloaded via the wellknown DS1102 card of dSPACE GmbH, including a processor TMS320C30 with two 16-bit and two 12-bit A/D converters after analog filtration. The control law is sent to the two servo-distributors via two 12-bit D/A converters. The value of the sampling period is $4 \mathrm{~ms}$. A more detailed description and the main characteristics of the system can be found in the PRC/GDR reports (13, 14). 


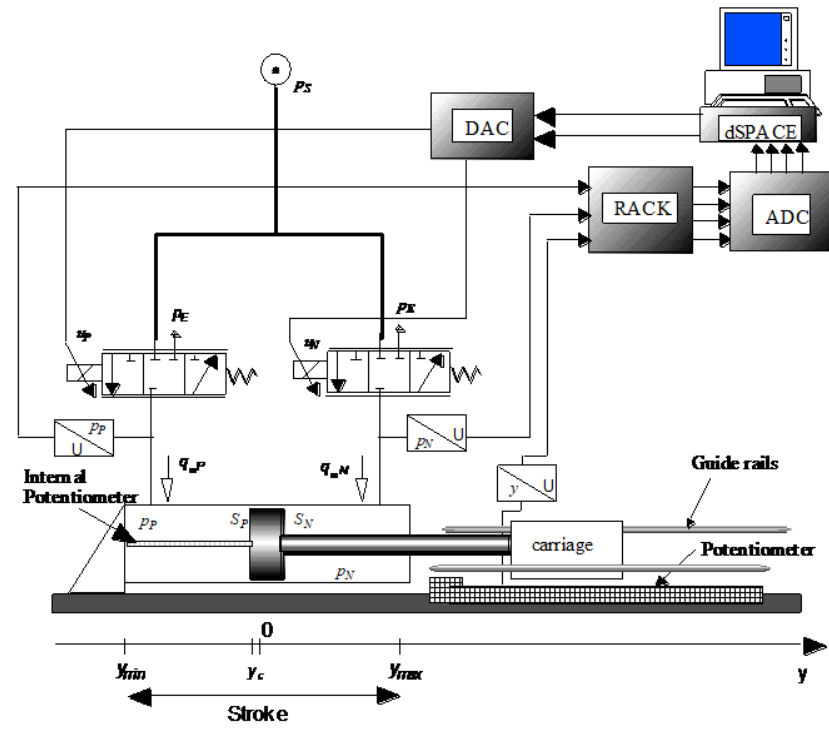

Fig. 1 The electropneumatic system.

\section{ELECTROPNEUMATIC SYSTEM MODELLING}

\subsection{Physical model}

\subsubsection{Servo-distributor model}

Our research team in collaboration with the AscoJoucomatic Company (15) has developed the Servotronic servo-distributor. So the main physical characteristics of this servo-distributor are wellknown and a good model for simulation has been established from many measurements and estimations of the different physical parameters (16). The two servo-distributors are assumed to be identical.

If the transitional mass flow rates are assumed to be negligible at each instant during the spool displacement, the output mass flow rate of the servo-distributor for a spool position is the same as the one obtained in steady state for the same spool position and the same pressure conditions. So the servo-distributor model can be divided in two parts. The first part corresponds to the positioning dynamics of the spool and depends mainly on the electromechanical system and the second part corresponds to the flow stage model obtained in steady state.

The spool position is controlled by a local state feedback using position, velocity and acceleration, with a little integral action. One of the advantages
Journal of SYSTEMS AND CONTROL ENGINEERING Special Issue 'Controls in Fluid Power Systems"

of this position control is the negligible hysteresis between the spool position and the input voltage. In our case, the bandwidth of the Servotronic servo-distributors and the actuator are respectively about $170 \mathrm{~Hz}$ and $2.4 \mathrm{~Hz}$. Using the singular perturbation theory, Bouhal (17) has shown that the faster dynamic can be neglected in the control model. The servo-distributor is then reduced to the static mass flow stage model.

The figure 2 shows the classical symbolic representation of the flow stage of a 3/2-way servo-distributor.

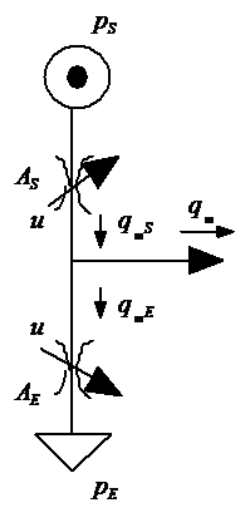

Fig. 2 Wheatstone half bridge representation.

This figure shows the two restrictions called $A_{S}$ and $A_{E}$ whose sections vary with the spool position and therefore with the control. In order to establish a mathematical model of such power modulators flow stages, many works in the literature present approximations from the use of the physical laws with the modelling of the geometric variations of the restrictions areas $A_{S}$ and $A_{E}(\mathbf{1 8}, \mathbf{1 9})$. These methods require a local characterisation $(\mathbf{2 0})$ of the power modulator.

Sesmat (15) made a complete study of the servodistributor Servotronic where all circuits of fluid flow and their influence on the flow stage characteristics are shown. This means that the Wheatstone half bridge representation of figure 2 is a too simplified one because all circuits of fluid flow are not taken into account (especially the leakage circuit).

Therefore in the following, a static flow stage mathematical model issued from the global characterisation is presented. This global or half bridge characterisation corresponds to the 
measurement of the output mass flow rate $q_{m}$ according to input control $u$ and the output pressure $p$. This means that the experimental characterisation is made on the overall flow circuits of the servo-distributor. This characterises the component taken as a whole ("black box").

The global characterisation has the advantage of obtaining simply, by projection of the characteristics series $q_{m}(u, p)$ (figure 3 ) on the different planes:

- mass flow rate characteristics series ("pressure - mass flow rate" plan), figure 4,

- mass flow rate gain characteristics series ("input control - mass flow rate" plan), figure 5.

- pressure gain characteristics series ("input control - pressure" plan), figure 6 .

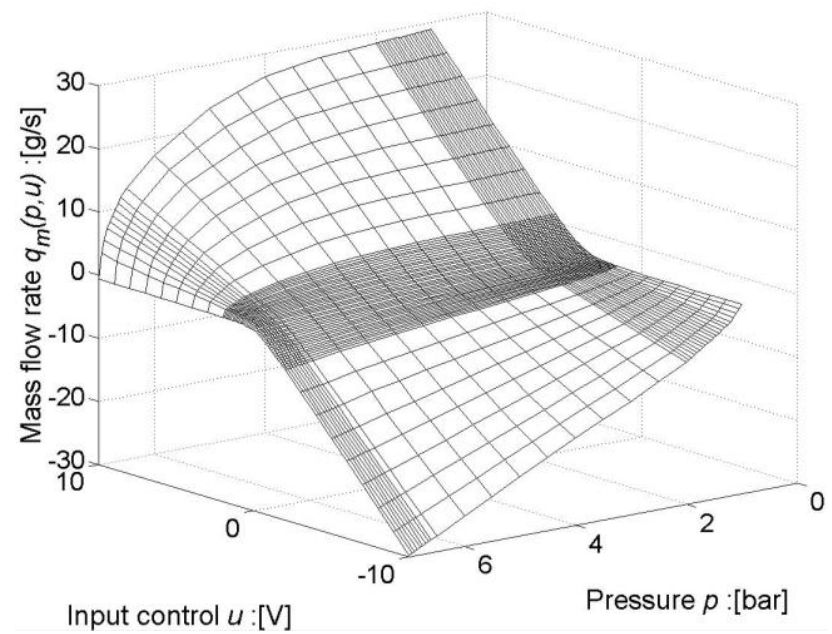

Fig. 3 Servo-distributor static characteristics.

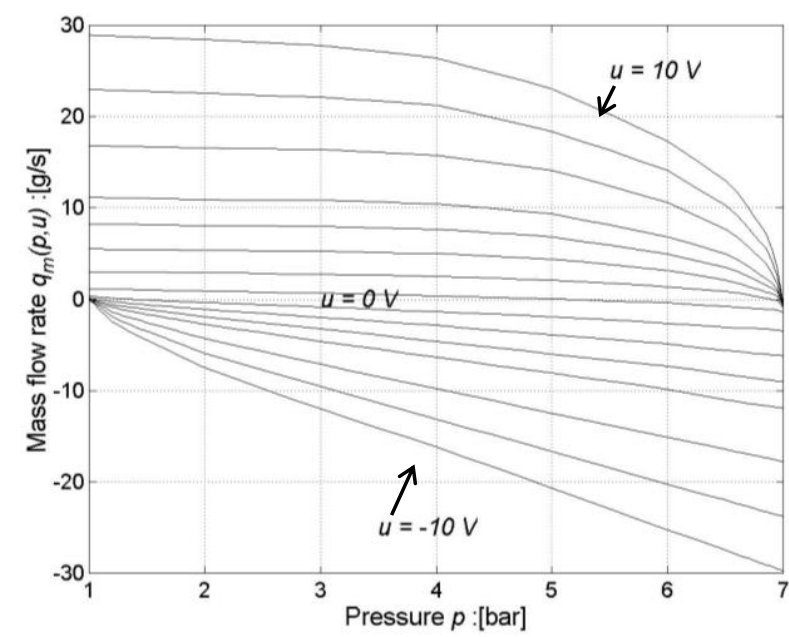

Fig. 4 Mass flow rate characteristics series.

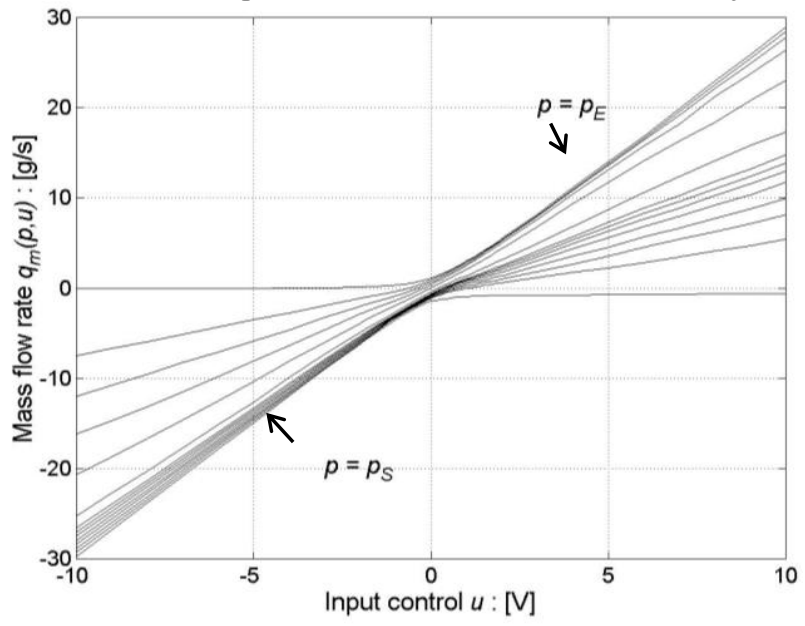

Fig. 5 Mass flow rate gain characteristics series.

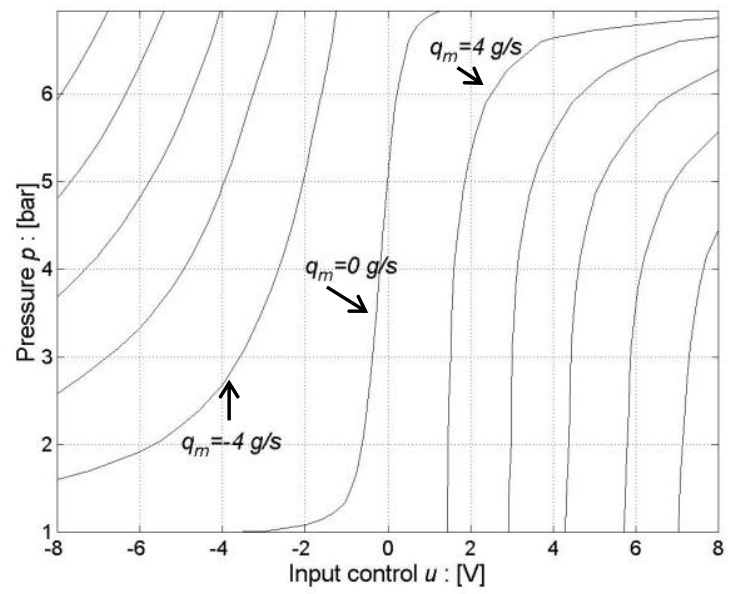

Fig. 6 Pressure gain characteristics series for different mass flow rate (incremented by $4 \mathrm{~g} / \mathrm{s}$ ).

For the great values of control input, the mass flow rate characteristics curves look like the classical mass flow rate characteristics of a compressible fluid in turbulent regime through a convergent nozzle. This characteristic is given by the physical laws (21) and can be characterised using the approximation from the ISO 6358 norm (22). The mass flow rate law in each restriction has the following form coming from the physical laws:

$$
q_{m}\left(u, p_{\text {down }} p_{u p}\right)=A \frac{p_{u p}}{\sqrt{T_{u p}}} C_{q}\left(\frac{p_{\text {down }}}{p_{u p}} \operatorname{or}\left(p_{u p}-p_{\text {down }}\right) \text { or } u \text { or } R e\right) C_{m}\left(\frac{p_{\text {down }}}{p_{u p}}\right)
$$

The mass flow rate coefficient $C_{q}$ is generally used as being only dependent on the pressure and the type of the restriction geometry. $C_{m}$ is the mass flow rate parameter depending on the pressures ratio by the following expressions: 
- in subsonic regime, $\frac{p_{\text {down }}}{p_{u p}}>b$ :

$C_{m}\left(\frac{p_{\text {down }}}{p_{\text {up }}}\right)=\sqrt{\frac{\gamma}{r} \frac{2}{\gamma-1}\left(\left(\frac{p_{\text {down }}}{p_{\text {up }}}\right)^{\frac{2}{\gamma}}-\left(\frac{p_{\text {down }}}{p_{\text {up }}}\right)^{\frac{\gamma+1}{\gamma}}\right)}$

- in sonic regime, $\frac{p_{\text {down }}}{p_{u p}} \leq b$ :

$C_{m}\left(\frac{p_{\text {down }}}{p_{\text {up }}}\right)=\sqrt{\frac{\gamma}{r}\left(\frac{2}{\gamma+1}\right)^{\frac{\gamma+1}{\gamma-1}}}$

The figure 4 shows clearly the nonlinear character of the mass flow rate according to pressure.

The mass flow rate gain characteristics give an idea of the variation of the restriction sections that occur during the fluid flow according to control input $u$. The figure 5 shows clearly the nonlinear character of these for small values of $u$.

The pressure gain characteristic is used to determine the equilibrium points of the global system in static regime for a given mass flow rate, generally equal to zero. This characteristic is thereby very important because it affects the steady state error.

The results of this global characterisation can be introduced in simulation programs either under a table form or under a multivariable polynomial form (23).

\subsubsection{Actuator model}

The actuator model can be obtained using two physical laws: the first giving the pressure dynamics in a chamber with variable volume and the second being the fundamental mechanic relation.

The pressure evolution law in a chamber with variable volume is obtained with the following assumptions $(\mathbf{2 4}, \mathbf{2 5})$ :

- the air is a perfect gas and its kinetic energy is negligible in the chamber,

- the pressure and the temperature are homogeneous in each chamber,

- the process is polytropic characterised by coefficient $k$.
The model of the cylinder and load assembly is given by the equations system (4).

$$
\begin{aligned}
& \left\{\begin{array}{l}
\frac{d p_{P}}{d t}=\frac{k r T_{s}}{V_{P}(y)}\left[q_{m}\left(u_{P}, p_{P}\right)-\frac{S_{P}}{r T_{s}} p_{P} v\right] \\
T_{P}=T_{P 0}\left(\frac{p_{P 0}}{p_{P}}\right)^{\left(\frac{1-k}{k}\right)} \\
\frac{d p_{N}}{d t}=\frac{k r T_{s}}{V_{N}(y)}\left[q_{m}\left(u_{N}, p_{N}\right)+\frac{S_{N}}{r T_{s}} p_{N} v\right] \\
T_{N}=T_{N 0}\left(\frac{p_{N 0}}{p_{N}}\right)^{\left(\frac{1-k}{k}\right)} \\
\frac{d v}{d t}=\frac{1}{M}\left[S_{P} p_{P}-S_{N} p_{N}-f_{v} v-F_{f}(v)-F_{e x t}\right] \\
\frac{d y}{d t}=v
\end{array}\right. \\
& \text { where }\left\{\begin{array} { l } 
{ V _ { P } ( y ) = V _ { P } ( 0 ) + S _ { P } y } \\
{ V _ { N } ( y ) = V _ { N } ( 0 ) - S _ { N } y }
\end{array} \text { with } \left\{\begin{array}{l}
V_{p}(0)=V_{D P}+S_{P} \frac{\text { Stroke }}{2} \\
V_{N}(0)=V_{D N}+S_{N} \frac{\text { Stroke }}{2}
\end{array}\right.\right.
\end{aligned}
$$

$\mathrm{V}_{\mathrm{P}}(0)$ and $\mathrm{V}_{\mathrm{N}}(0)$ are the volumes of the chambers for the zero position and $V_{D X}$ are dead volumes present at each extremity of the cylinder.

The dynamic evolution of each pressure in the two cylinder chambers $P$ and $N$ is given by the two first order differential equations of this system.

The mass flow rate leakage between the two chambers is classically neglected in the case of an in line pneumatic cylinder.

The last modelling assumption (polytropic process) leads to an algebraic equation between pressure and temperature of each chamber.

The supply and exhaust pressures are assumed to be constant in experimental conditions.

The two last equations of (4) come from the application of the main principle of classic mechanics to the mechanical part in movement.

\subsection{Model for the control}

\subsubsection{Additional assumptions}

The previous physical model of the electropneumatic system can not be used for synthesize control laws without any additional assumptions.

The first assumption concerns the temperature variation with respect to its average value. This variation is generally negligible so the temperature 
in each chamber may be considered equal to the supply temperature. Then: $T_{P}=T_{N}=T_{S}$.

In the control model, the different frictions (except viscous), must be neglected because they depend on velocity but also on experimental conditions like temperature, atmospheric pressure, time of experiment... So it is difficult to identify them before all the tests and to be sure that they are going to keep constant values during the tests (26). Furthermore, only one control is used with opposite sign on the two servo-distributors (so $u_{P}=-u_{N}=u$ ).

Consequently, these assumptions lead finally to a fourth order control model written in the form:

$$
\left\{\begin{array}{l}
\frac{d p_{P}}{d t}=\frac{k r T_{s}}{V_{P}(y)}\left[q_{m}\left(u, p_{P}\right)-\frac{S_{P}}{r T_{s}} p_{P} v\right] \\
\frac{d p_{N}}{d t}=\frac{k r T_{s}}{V_{N}(y)}\left[q_{m}\left(-u, p_{N}\right)+\frac{S_{N}}{r T_{s}} p_{N} v\right] \\
\frac{d v}{d t}=\frac{1}{M}\left[S_{P} p_{P}-S_{N} p_{N}-f_{v} v-F_{e x t}\right] \\
\frac{d y}{d t}=v
\end{array}\right.
$$

\subsubsection{Nonlinear affine model}

For the nonlinear control synthesis, the model must be a linear function of the control input what it is called affine in control (27). For this, the equations system (5) shows that the control input variable which is the control input voltage of the power modulator appears in a nonlinear manner. A new control law variable is chosen and a method to obtain this linearity from the global characterisation described in the modelling part of this paper is proposed.

A polynomial multivariable approximation will be made with a least square algorithm. The choice of the expression of the mass flow rate is based essentially on the expressions $(1,2$, and 3$)(\mathbf{2 3})$ to which a function allowing to take into account the mass flow rate leakage is added. The expression is as follows:

$$
q_{m}(u, p)=\varphi(p)+\psi(p, \operatorname{sgn}(\Gamma(u))) \Gamma(u)
$$

$\Gamma(u)$ is a function whose evolution is similar to the evolution of the equivalent section restriction that crosses the fluid as a function of spool position.
$\Gamma(u)$ will be therefore deduced from the mass flow rate gain characteristics series.

$\varphi(p)$ is a function whose evolution corresponds to the mass flow rate leakage.

$\psi(p, \operatorname{sgn}(\Gamma(u)))$ is a function whose evolution is similar to the one described by the expression of mass flow rate laws (1). It is a function of the input control sign because the function is different for the inlet $(\Gamma(u)>0)$ and for the exhaust $(\Gamma(u)<0)$. The form of the mass flow rate characteristics (figure 4) justifies this approximation by two distinct functions, one defined for $u>0$ and the other for $u<0$.

These functions must have bijectivity properties and $\Gamma(u)$ is defined as following: $\Gamma(u)=-\Gamma(-u)$ and $\Gamma(0)=0$. This last property is justified by the fact that the input control of the electropneumatic actuator is in single input that is to say that the two servo distributors have the same control input signal but of inverse signs.

The number of points acquired during the characterisation being sufficient and their density greater in the nonlinear zones, weighting coefficients are not used with the algorithm. The quality of the approximation is given by a criterion called multiple correlation coefficient. Moreover in our case, a second criterion is fixed a posteriori, it corresponds to the error on the pressure gain characteristic obtained for a zero mass flow rate.

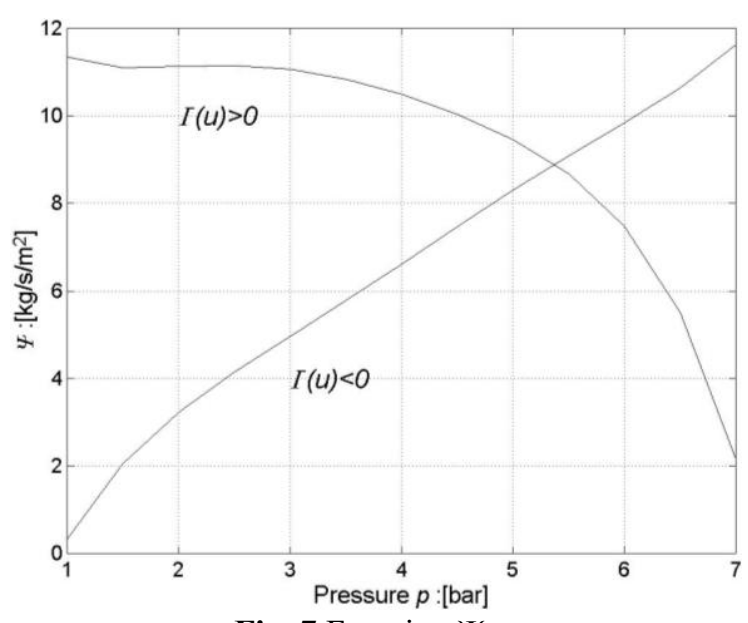

Fig. 7 Function $\Psi$. 


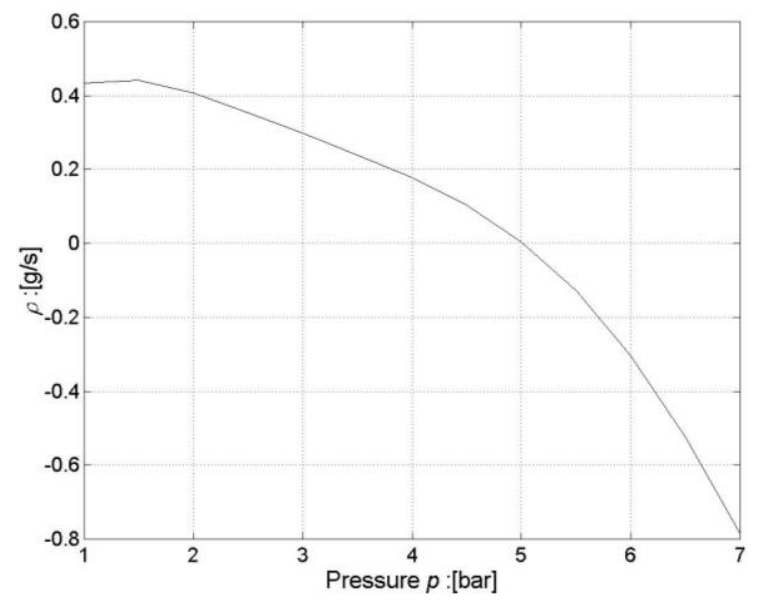

Fig. 8 Function $\varphi$.

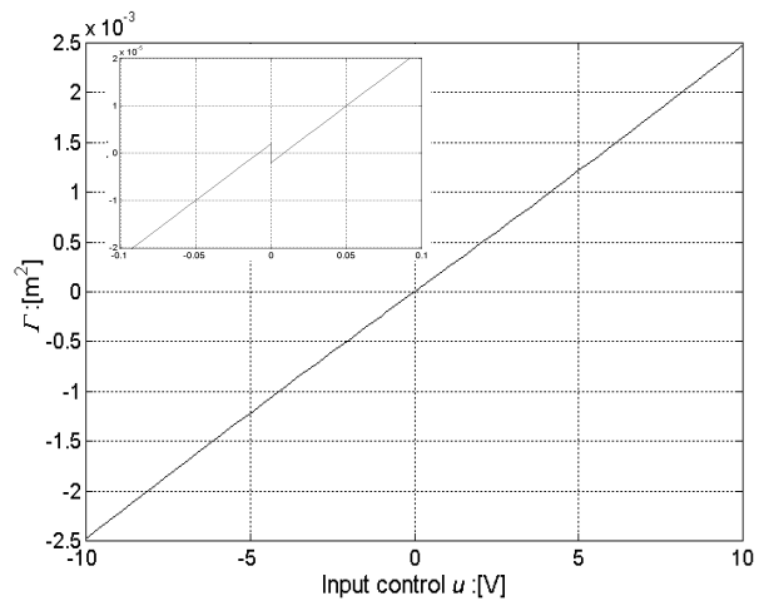

Fig. 9 Function $\Gamma$.

The figures 7, 8 and 9 present the results where $\varphi(p), \quad \psi(p, \operatorname{sgn}(\Gamma(u))), \quad \Gamma(u)$ have degree equal to five, five and two respectively.

The mass flow rate errors obtained with this approximation are more important for the output pressure near supply and atmospheric pressures. These results could be improved by increasing the polynomial degree of $\psi(p, \operatorname{sgn}(\Gamma(u)))$ or by giving more importance to some measure points. The normal working pressures rarely reach these limit pressures, thereby these obtained results can be judged satisfactory.

As comparison, the pressure gain characteristics for a zero mass flow rate value obtained with the global method (6) and the local method (20) are compared with the experimental one on figure 10. The nonlinear method affine in the control obtained from the global characterisation gives better result than with the local method.

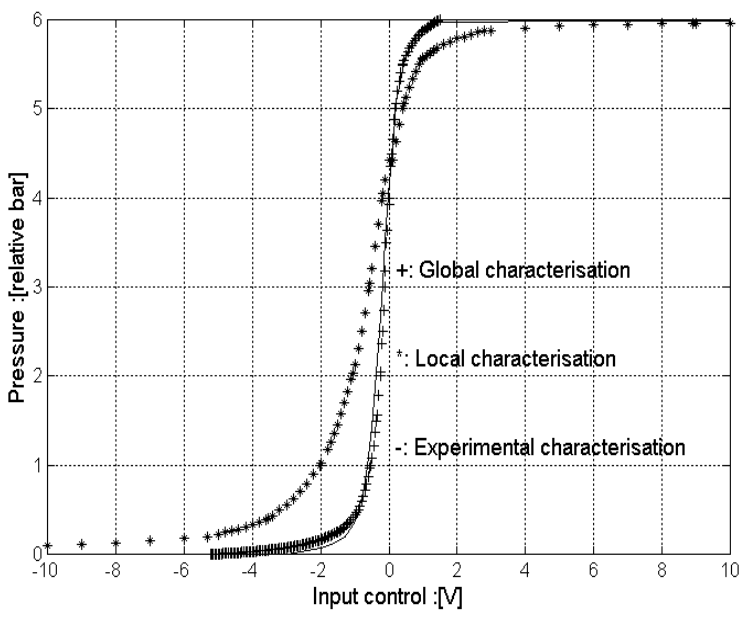

Fig. 10 Pressure gain comparison.

Notice that from this polynomial form (6), the linearised tangent model and the equilibrium points may be easily obtained.

Finally, the nonlinear control model affine in the control is written:

$$
\left\{\begin{array}{l}
\frac{d p_{P}}{d t}=\frac{k r T_{s}}{V_{p}(y)}\left[\varphi\left(p_{P}\right)-\frac{S_{P}}{r T_{s}} p_{P} v\right]+\frac{k r T_{s}}{V_{P}(y)} \psi\left(p_{p}, \operatorname{sgn}(\Gamma(u))\right) \Gamma(u) \\
\frac{d p_{N}}{d t}=\frac{k r T_{s}}{V_{N}(y)}\left[\varphi\left(p_{N}\right)+\frac{S_{N}}{r T_{s}} p_{N} v\right]-\frac{k r T_{s}}{V_{N}(y)} \psi\left(p_{N}, \operatorname{sgn}(-\Gamma(u))\right) \Gamma(u) \\
\frac{d v}{d t}=\frac{1}{M}\left[S_{P} p_{P}-S_{N} p_{N}-f_{v} v-F_{e x t}\right] \\
\frac{d y}{d t}=v
\end{array}\right.
$$

\subsubsection{Equilibrium set and tangent} linearisation

For a single input nonlinear model of the form $\underline{\dot{x}}=f(\underline{x}, u)$, the equilibrium set is defined by $\underline{\dot{x}}=f\left(\underline{x}^{e}, u^{e}\right)=0$. So in our case the equilibrium set $\left\{y^{e}, v^{e}, p_{P}^{e}, p_{N}^{e}, u^{e}\right\}$ is deduced from system (5):

$$
\left\{\begin{array}{l}
y^{e} \\
v^{e}=0 \\
S_{P} p_{P}^{e}-S_{N} p_{N}^{e}-F_{e x t}^{e}=0 \\
q_{m}\left(u^{e}, p_{P}^{e}\right)=0 \\
q_{m}\left(-u^{e}, p_{N}^{e}\right)=0
\end{array}\right.
$$

The three last equations can be solved graphically as shown in figure 11 to obtain the three unknown variables $p_{p}^{e}, p_{N}^{e}$ and $u^{e}(\mathbf{2 8})$. This figure shows the experimental pressure gain characteristic and the pressure force gain characteristic $\left(S_{P} p_{P}-S_{N} p_{N}\right)(u)$ deduced from it, both for a zero mass flow rate. These curves are obtained from the servodistributor static characteristics (figure 3). They 
are monotonous and strictly increasing so for any equilibrium position value and for a given external force there is only one equilibrium point defined by:

$$
\left\{\mathrm{y}^{\mathrm{e}}, \mathrm{v}^{e}=0, p_{P}^{e}\left(F_{e x t}^{e}\right), p_{N}^{e}\left(F_{\text {ext }}^{e}\right), u^{e}\left(F_{e x t}^{e}\right)\right\}
$$

Consequently, the dimension of the equilibrium set is the same as the number of input of the system, which is a necessary condition to prove that the tangent linearised model is a controllable system.

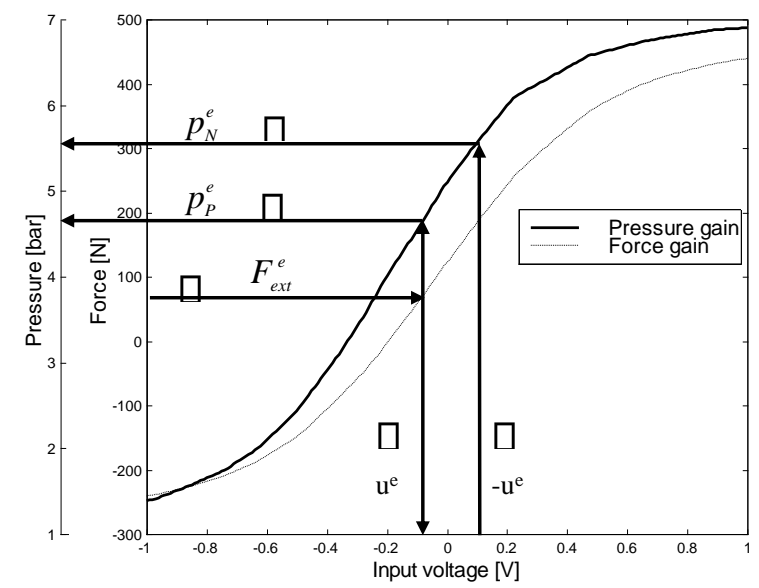

Fig. 11 Pressure force gain and Pressure gain characteristics at zero mass flow rate.

The tangent linearised model has the following form (11), with variation near equilibrium set:

$\left\{\delta p_{P}=p_{P}-p_{P}^{e}, \delta p_{N}=p_{N}-p_{N}^{e}, \delta v=v-v^{e}, \delta y=y-y^{e}, \delta u=u-u^{e}\right\}$

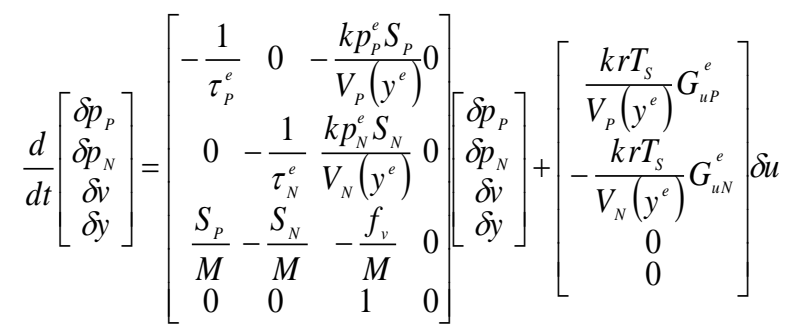

The time constants $\tau_{P}^{e}$ and $\tau_{N}^{e}$ are:

$\tau_{P}^{e}=\frac{V_{P}\left(y^{e}\right)}{k r T_{S} C_{P P P}^{e}} \quad$ and $\quad \tau_{N}^{e}=\frac{V_{N}\left(y^{e}\right)}{k r T_{S} C_{P_{N} N}^{e}}$

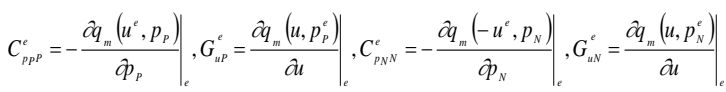

deduced from the servo-distributor static characteristics in figure 3.
Journal of SYSTEMS AND CONTROL ENGINEERING Special Issue 'Controls in Fluid Power Systems"

\subsubsection{Reduced tangent linearised model}

In the pneumatic field, the conventional position control law consists of position, velocity and acceleration feedbacks. Using acceleration feedback instead of pressures feedbacks or differential pressure feedback can be justified by the fact that an external perturbation force quickly influences acceleration.

To obtain a third order model with position, velocity and acceleration state variables, Kellal et al (29) proposed to replace each time constant of each chamber by an average time constant $\tau_{m}^{e}$ (geometric mean). Then the third order model is :

$\frac{d}{d t}\left[\begin{array}{l}y \\ v \\ a\end{array}\right]=\left[\begin{array}{ccc}0 & 1 & 0 \\ 0 & 0 & 1 \\ 0-\omega_{o l}{ }^{2}-2 \zeta_{o l} \omega_{o l}\end{array}\right]\left[\begin{array}{l}y \\ v \\ a\end{array}\right]+\left[\begin{array}{l}0 \\ 0 \\ b\end{array}\right] u$

The damping coefficient is: $\zeta_{o l}=\frac{1}{2 \omega_{o l}}\left(\frac{1}{\tau_{m}^{e}}+\frac{f_{v}}{M}\right)$

$b=\frac{k r T_{S}}{M}\left[\frac{S_{P} G_{u P}^{e}}{V_{P}\left(y^{e}\right)}+\frac{S_{N} G_{u N}^{e}}{V_{N}\left(y^{e}\right)}\right]$

The open loop pulsation is $\omega_{o l}=\sqrt{\omega_{c y l}{ }^{2}+\frac{f_{v}}{\tau_{m}^{e} M}}$

with

$$
\omega_{c y l}=\sqrt{\frac{k}{M}\left(\frac{S_{P}{ }^{2} p_{P}^{e}}{V_{P}\left(y^{e}\right)}+\frac{S_{N}{ }^{2} p_{N}^{e}}{V_{N}\left(y^{e}\right)}\right)}
$$

\section{POINT TO POINT CONTROL}

\subsection{Fixed and scheduling gains control laws.}

The reduced model of third order (13) obtained by linearisation around an equilibrium state is used in this part to synthesize a state feedback law for point to point position control.

In industrial processes two objectives have to be respected: good dynamic behaviour and a minimum steady state error without overshooting. These criteria must be true for every desired position and for different displacement amplitudes. The results are presented in this paper in terms of repeatability, in order to limit the influence of stochastic perturbation like dry friction variation, supply pressure evolution, electrical noise... 
A classical state feedback has been implemented and tested :

$u=u^{e}+K_{y}\left(y_{d}-y\right)-K_{v} v-K_{a} a$

The state feedback coefficients are obtained by fixing a desired behaviour for the closed loop system. To conform with industrial criteria, a third order characteristic polynomial with a dominant second order is chosen $(\mathbf{3}, \mathbf{2 4})$

$\left(\lambda+\frac{1}{\tau_{c l}}\right)\left(\lambda^{2}+2 \omega_{c l} \zeta_{c l} \lambda+\omega_{c l}{ }^{2}\right)$

$\left\{\begin{array}{l}\tau_{c l}=\frac{1}{6 \omega_{c l}} \\ \zeta_{c l}=1\end{array}\right.$

$\omega_{c l}$ proportionnal to $\omega_{o l}$

Simple calculus leads to:

$K_{y}=\frac{6 \omega_{c l}{ }^{3}}{b}, K_{v}=\frac{\left(13 \omega_{c l}{ }^{2}-\omega_{o l}{ }^{2}\right)}{b}, K_{a}=\frac{\left(8 \omega_{c l}-2 \zeta_{o l} \omega_{o l}\right)}{b}$

Expressions (17) and (21) show that the feedback gains depend on the position. Figure 12 shows these variations with position for a closed loop dynamic calculated for each position with $\omega_{c l}(y)=1.2 \omega_{o l}(y)$.

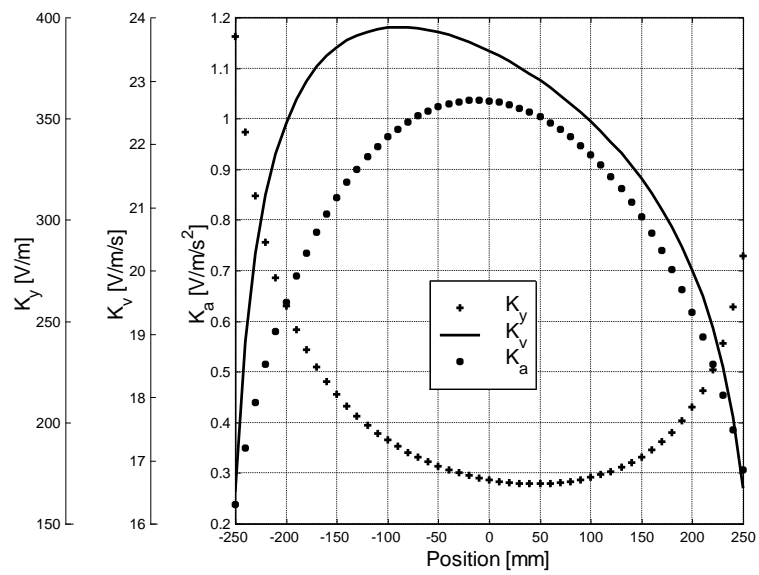

Fig. 12 Evolution of feedback gains $\mathrm{K}_{\mathrm{y}}, \mathrm{K}_{\mathrm{v}}, \mathrm{K}_{\mathrm{a}}$ for $\omega_{c l}(y)=1.2 \omega_{o l}(y)$.

The gains used for the fixed gain control law are those calculated in the central position $y_{c}$, this corresponds to the smallest value of the cylinder natural pulsation (see expression (17)). It is easy to show using the Routh Hurwitz criterion that this choice assures the asymptotic stability for all positions.

With these fixed gains, the behaviour of the system should be different in extremities of the stroke. However, for electropneumatic systems this is not true for two reasons shown in figure 13:

-Firstly this figure shows the evolution of the poles for a control law calculated in central position and applied to different other positions. All along the stroke, the imaginary part of the pole is negligible in comparison with real part that leads to a step reponse without oscillation.

-Secondly the dynamic behaviour is nearly the same because for every position of the piston the two complex poles are like one double real pole which stays nearly constant in every position (see zoom). So these poles impose the dynamic behaviour because the third pole is in the ratio of six or more.

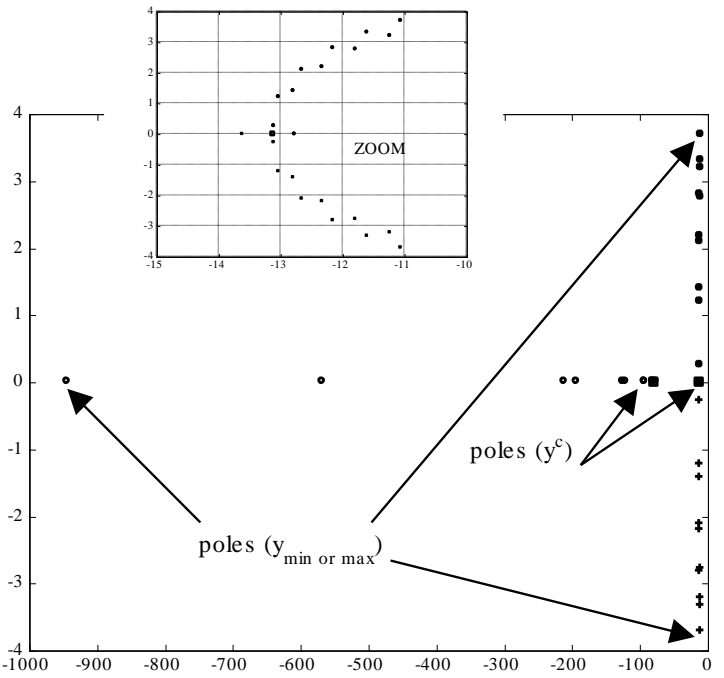

Fig. 13 Poles evolution in closed loop for different equilibrium positions for fixed gains $\omega_{c l}(y)=1.2 \omega_{o l}(y)$.

The control law with scheduling gains is obtained by approximating in the least square sense the curves shown in figure 12 with a fourth order polynomial function. So the appropriate control law may be written in the form:

$$
u\left(y_{d}\right)=u^{e}+K_{y}\left(y_{d}\right)\left(y_{d}-y\right)-K_{v}\left(y_{d}\right) v-K_{a}\left(y_{d}\right) a
$$

Equilibrium values do not depend on the desired position, so $u^{e}\left(y_{d}\right)=u^{e}$. This control law takes advantage of the natural characteristics of 
electropneumatic systems and leads to its best performances in closed loop, due to the higher natural system dynamic near the cylinder ends.

\subsection{Comparison of experimental results}

In order to compare the experimental results obtained with the two different control laws, a kind of "industrial benchmark" has been developed. Table 1 summarises the results obtained for fixed and scheduling gains for small movements around the central position and near the two extreme positions of the actuator. In each case the magnitude of the movement is only $10 \%$ of the total stroke. So we can consider that the tangent linearised model is valid for every desired position. All tests presented in this table have been carried one hundred times in the same conditions. In terms of repeatability, it is interesting to note that the standard deviation $(\sigma)$ is nearly independent of the position: a value around 0.1 millimetre is obtained for the fixed gains control law and about $30 \%$ less for scheduling gains.

\begin{tabular}{|c|c|c|c|c|c|c|c|c|c|c|c|c|}
\hline Control law & \multicolumn{6}{|c|}{ Fixed Gains } & \multicolumn{6}{|c|}{ Scheduling Gains } \\
\hline Desired & \multirow{2}{*}{\multicolumn{2}{|c|}{ 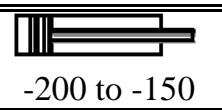 }} & \multirow{2}{*}{\multicolumn{2}{|c|}{ תב }} & \multirow{2}{*}{\multicolumn{2}{|c|}{ صـ }} & \multirow{2}{*}{\multicolumn{2}{|c|}{ ת }} & \multirow{2}{*}{\multicolumn{2}{|c|}{ 25 }} & \multirow{2}{*}{\multicolumn{2}{|c|}{ שص }} \\
\hline Position [mm] & & & & & & & & & & & & \\
\hline Piston direction & - & + & - & + & - & + & - & + & - & + & - & + \\
\hline$\sigma[\mathrm{mm}]$ & 0.114 & 0.121 & 0.120 & 0.110 & 0.006 & 0.116 & 0.027 & 0.021 & 0.089 & 0.105 & 0.035 & 0.119 \\
\hline Mean $\varepsilon[\mathrm{mm}]$ & 0.41 & 0.21 & 0.27 & 0.01 & 0.40 & 0.20 & 0.35 & 0.13 & 0.61 & 0.20 & 0.42 & 0.29 \\
\hline $\operatorname{Max} \varepsilon[\mathrm{mm}]$ & 0.61 & 0.59 & 0.32 & 0.30 & 0.50 & 0.23 & 0.38 & 0.17 & 0.74 & 0.56 & 0.46 & 0.39 \\
\hline Mean pos [mm] & -199.59 & -149.79 & -24.73 & 24.99 & 150.40 & 199.80 & -199.65 & -149.87 & -24.39 & 25.20 & 150.42 & 199.71 \\
\hline$\tau_{r} *[\mathrm{~ms}]$ & 253 & 263 & 251 & 259 & 259 & 272 & 141 & 220 & 262 & 248 & 243 & 165 \\
\hline$v_{\max }[\mathrm{mm} / \mathrm{s}]$ & 252 & 247 & 244 & 264 & 222 & 253 & 427 & 313 & 244 & 264 & 251 & 393 \\
\hline$a_{\max }\left[\mathrm{m} / \mathrm{s}^{2}\right]$ & 4.56 & 4.70 & 4.35 & 4.59 & 3.48 & 4.59 & 6.39 & 4.59 & 4.05 & 4.59 & 4.75 & 4.59 \\
\hline
\end{tabular}

* $\tau_{r}=$ response time between 10 and $90 \%$ of the movement

Table 1 Experimental results with fixed and scheduling gains control laws.

As explained in paragraph 4.1, the results obtained with the scheduling gain control law are more satisfactory than with fixed gains, particularly in terms of displacement velocity near the cylinder ends, which consequently have a satisfactory improvement. Table 2 and figure 14 show the main results. For example, on the extremity the improvement in time response calculated between 10 and $90 \%$ of the movement is about $40 \%$.

\begin{tabular}{||c||c|c|c|c||}
\hline \multicolumn{1}{|c||}{$\begin{array}{c}\text { Desired Position } \\
{[\mathrm{mm}]}\end{array}$} & \multicolumn{2}{|c||}{$\begin{array}{c}|c| \mid \\
-200 \text { to }-150\end{array}$} & \multicolumn{2}{|c||}{150 to 200} \\
\hline Direction & - & + & - & + \\
\hline$\sigma$ & \multicolumn{4}{|c||}{$-43 \%$} \\
\hline Mean $\varepsilon[\mathrm{mm}]$ & -0.08 & -0.36 & -0.11 & +0.22 \\
\hline$\tau_{r}$ & $-43 \%$ & $-17 \%$ & $-16 \%$ & $-39 \%$ \\
\hline$v_{\max }$ & $+69 \%$ & $+27 \%$ & $+13 \%$ & $+55 \%$ \\
\hline
\end{tabular}

Table 2 Improvement of the scheduling gains control law compared to fixed gains.
It will of course be interesting to compare results for other different magnitudes of piston displacement.

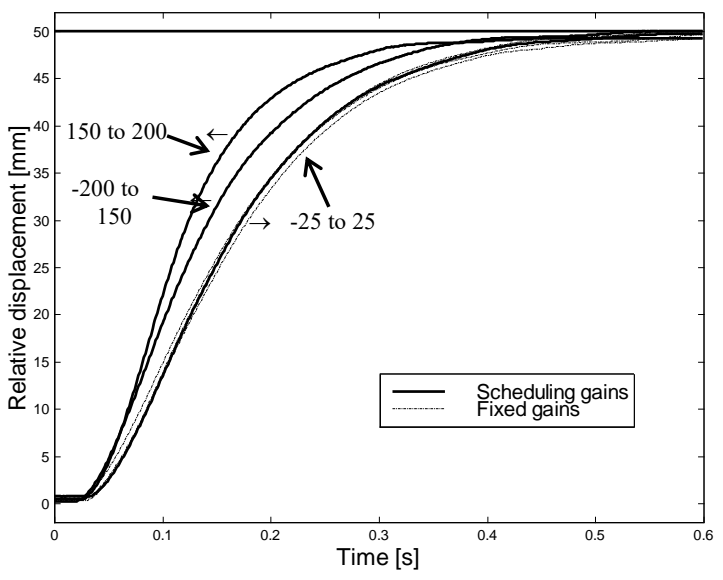

Fig. 14 Experimental results. 


\section{TRACKING}

\subsection{Choice of admissible trajectories}

Under the hypothesis that the servo-distributor spool time displacement is negligible, the relative order of the position output of the electropneumatic system is three. This means that there are "three integrators" between the control input of the system and the output, which is the cylinder piston position. So it means that the electropneumatic system can only track position trajectories at least three times differentiable. For example a polynomial function of degree three satisfies this condition. But to respect industrial necessity, the trajectory has been chosen with physical criteria, in terms of maximum velocity, maximum acceleration and duration with constant velocity or acceleration. So the trajectory corresponds to a constant piecewise time function for the jerk (acceleration time derivative) and is generated by a triple integrator reference model.

All results presented in this section have been obtained for two different trajectories with the same movement amplitude (90\% of total stroke) and the same time displacement: 2.04 seconds (table 3). For the first trajectory the velocity is constant for about $90 \%$ of the displacement time, see figure $15 \mathrm{a}$, and for the second trajectory, there is a constant acceleration phase (for about $45 \%$ of movement), and an equal constant deceleration phase : see figure $15 \mathrm{~b}$.

\begin{tabular}{|l|c|c|}
\hline \multicolumn{1}{|c|}{ TRAJECTORY } & 1 & 2 \\
\hline Amplitude of movement [mm] & \multicolumn{2}{|c|}{400} \\
\hline Sampling period [ms] & \multicolumn{2}{|c|}{4} \\
\hline Duration of rod out [s] & \multicolumn{2}{|c|}{2.040} \\
\hline Duration of one cycle [s] & \multicolumn{2}{|c|}{9.996} \\
\hline Duration with constant jerk [ms] & 60 & 60 \\
\hline Duration with constant acc [ms] & 0 & 900 \\
\hline Duration with constant velocity [ms] & 1800 & 0 \\
\hline Maximum velocity [m/s] & 0.20 & 0.39 \\
\hline Maximum acceleration [m/s ${ }^{2}$ ] & 3.4 & 0.41 \\
\hline Maximum jerk [m/s $\mathrm{s}^{3}$ ] & 58 & 6.8 \\
\hline
\end{tabular}

Table 3 Main characteristics of the desired trajectories.

These two kinds of trajectories are very often used in industrial processes. Many robots are controlled with a constant velocity phase. This can be used in painting systems, for example. The limitation of acceleration and jerk is useful for positioning systems which carry delicate loads or dangerous liquids in containers (as in the chemical industry), it can be done with the second trajectory (fig 15b).

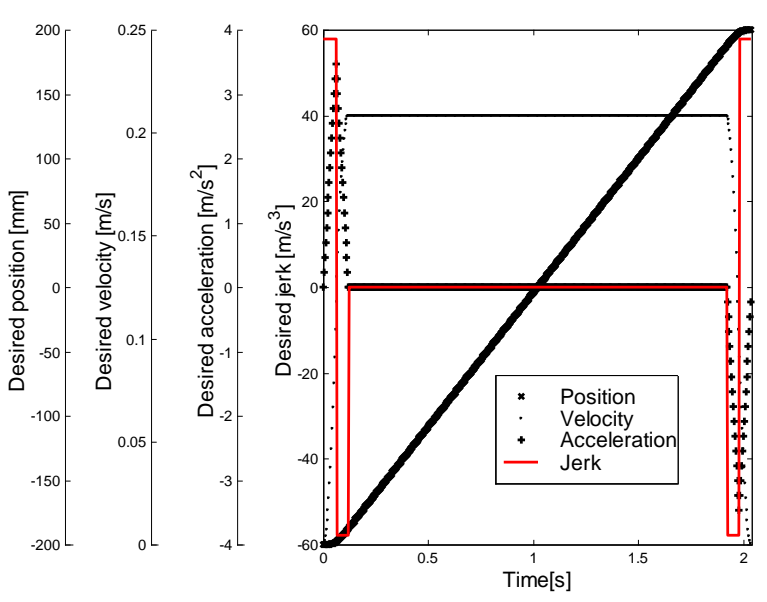

a Trajectory 1 with constant velocity.

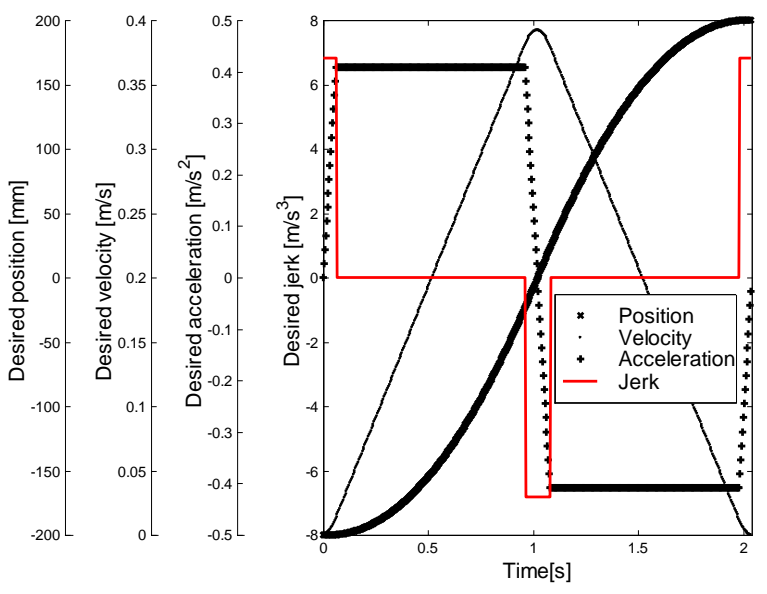

b Trajectory 2 with constant acceleration.

Fig. 15 Choice of desired trajectories.

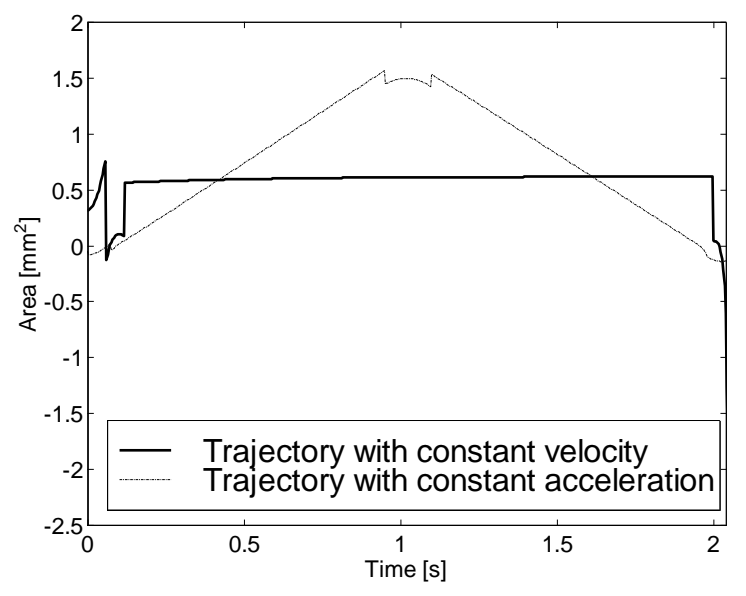

Fig. 16 Theoretical necessary section area of servodistributor. 
The choice of trajectory is also a problem of sizing: the control input must not reach its maximal value during tracking control. Using nonlinear control theory, Richard and Scavarda (20) have shown that it is possible to calculate the theoretical control law associated to a given cylinder position tracking. Sesmat et al (32) have proposed a procedure for verifying the servodistributor size: using the reduced inverse model, the servo-distributor control area is calculated and its value must have a value smaller than a chosen fraction of the nominal area. For the Servotronic servo-distributor this maximum area is $24 \mathrm{~mm}^{2}$. Figure 16 shows that the desired trajectories are both theoretically physically admissible by the system under consideration.

\subsection{Principle of tracking control}

In tracking control theory an appropriate feedback must transform the closed loop system into the same one as the reference model, which is a triple integrator in our case, as seen in the previous paragraph.

So the first feedback transforms the system as:

$\underline{\dot{z}}=I_{d} \underline{z}+B_{J} j_{c}$

where $I_{d}=\left[\begin{array}{l}010 \\ 001 \\ 000\end{array}\right] \quad B_{J}=\left[\begin{array}{l}0 \\ 0 \\ 1\end{array}\right]$ and $\underline{z}=\left[\begin{array}{l}y \\ v \\ a\end{array}\right]$

In the following, two ways to synthesize the first feedback are presented. Firstly the reduced linearised model (13) is used and fixed feedback gains are obtained (section 5.3). Secondly a nonlinear linearising control law is used (section 5.4).

With the first loop and the reference model, the state error vector is defined as $z_{\varepsilon}=z_{d}-\underline{z}$, so with:

$j_{\varepsilon}=j_{d}-j_{c} \quad \underline{\dot{z}_{\varepsilon}}=I_{d} \underline{z_{\varepsilon}}+B_{J} j_{\varepsilon}$

Without perturbations, with the same input as for the reference model, the closed loop system should have the same acceleration, velocity and position evolutions as the reference ones. There are however always uncertainties in the model and
Journal of SYSTEMS AND CONTROL ENGINEERING Special Issue 'Controls in Fluid Power Systems"

consequently the nonlinearities are not exactly compensated by the control law. Furthermore, the parameters of the nonlinear model generally vary with time, and force perturbations can occur. So a second loop is necessary for disturbance rejections.

The second feedback enables the dynamic cancellation of tracking errors to be fixed. Static state feedback is chosen with fixed gains calculated with the same procedure as for point to point control but with $\omega_{c l}=1.5 \omega_{o l}\left(y_{c}\right)$ :

$j_{\varepsilon}=-K_{2} \underline{z_{\varepsilon}} \quad$ with $\quad K_{2}=\left[\begin{array}{l}K_{y 2} \\ K_{v 2} \\ K_{a 2}\end{array}\right] \quad$ SO $\left\{\begin{array}{l}K_{y 2}=6 \omega_{c l}^{3} \\ K_{v 2}=13 \omega_{c l}^{2} \\ K_{a 2}=8 \omega_{c l}\end{array}\right.$

During the synthesis of the control law, dry friction has been neglected. To minimise the stiction phenomena, a boosting control is added during some sample times when desired jerk becomes no null and velocity measured is close to zero. This term, noted $\mathrm{u}_{\text {boost, }}$ transmits the required energy to the system so that it can escape from the stiction friction. This method could be compared with current overshoot in power converter devices in order to improve switching.

The principle of this tracking control is resumed by the figure 17 .

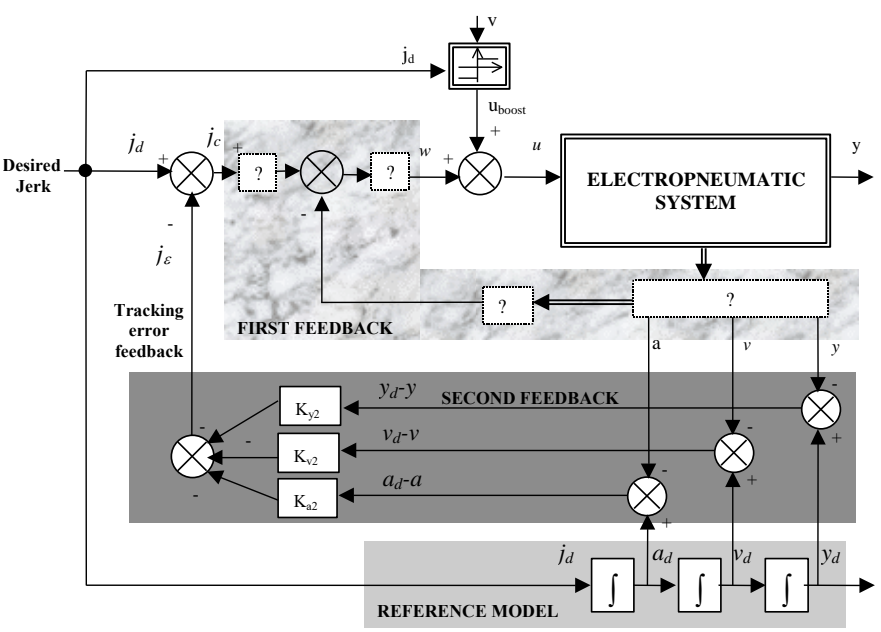

Fig. 17 Principle of tracking control.

\subsection{Linear tracking control}

Using the principle described above, the linear control tracking (33) is synthesized with the tangent linearised model described by expression (13), and having the form: 
$\underline{\dot{z}}=A \underline{z}+B u$

$$
A=\left[\begin{array}{ccc}
0 & 1 & 0 \\
0 & 0 & 1 \\
0 & -\omega_{o l}^{2}-2 \zeta_{o l} \omega_{o l}
\end{array}\right] \quad \text { and } \quad B=\left[\begin{array}{l}
0 \\
0 \\
b
\end{array}\right]
$$

The first loop gains are calculated from this reduced linearised model of the third order calculated in the cylinder central position which is the worst position for dynamic behaviour. This loop consists of a state feedback with fixed gains in position, velocity and acceleration (figure 18)

$u=-K_{1} \underline{z}+u_{c} \quad$ with

$$
K_{1}=\left[\begin{array}{l}
K_{y 1} \\
K_{v 1} \\
K_{a 1}
\end{array}\right] \text { so }\left\{\begin{array}{l}
K_{p 1}=0 \\
K_{v 1}=-\frac{\omega_{o l}^{2}}{b} \\
K_{a 1}=-\frac{2 \zeta_{o l} \omega_{o l}}{b}
\end{array}\right.
$$

The system is now equivalent to (23), then:

$u_{c}=\frac{1}{b} j_{c}$

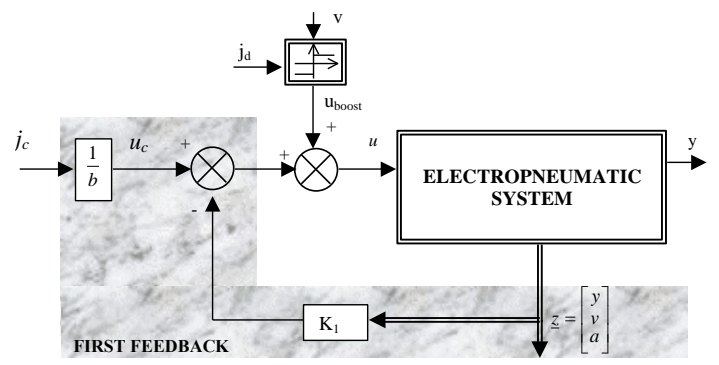

Fig. 18: Linear first feedback for linear tracking control.

With the second feedback, the linear control applied to the electropneumatic system is :

$$
\begin{aligned}
u=u_{b o o s t}- & K_{y 1} y-K_{v 1} v-K_{a 1} a \\
& +\frac{1}{b}\left(j_{d}+K_{y 2}\left(y_{d}-y\right)+K_{v 2}\left(v_{d}-v\right)+K_{a 2}\left(a_{d}-a\right)\right)
\end{aligned}
$$

\subsection{Nonlinear tracking control}

The electropneumatic model (7) is in the nonlinear affine form $\underline{\dot{x}}=f(\underline{x})+g(\underline{x}) U$.

$$
\underline{x}=\left[\begin{array}{c}
p_{P} \\
p_{N} \\
v \\
y
\end{array}\right] \text { and } U=\Gamma(u)
$$

$$
f(x)=\left(\begin{array}{c}
\frac{k r T_{s}}{V_{p}(y)}\left[\varphi\left(p_{p}\right)-\frac{S_{P}}{r T_{s}} p_{p} v\right] \\
\frac{k r T_{s}}{V_{N}(y)}\left[\varphi\left(p_{N}\right)+\frac{S_{N}}{r T_{s}} p_{N} v\right] \\
\frac{1}{M}\left[S_{P} p_{P}-S_{N} p_{N}-f_{v} v-F_{e r t}\right] \\
v
\end{array}\right) g(x)=\left(\begin{array}{c}
\frac{k r T_{s}}{V_{P}(y)} \psi\left(p_{p}, s g n(U)\right) \\
-\frac{k r T_{s}}{V_{N}(y)} \psi\left(p_{N}, s g n(-U)\right) \\
0 \\
0
\end{array}\right)
$$

A convenient way to linearised it for every position of the cylinder piston, is to use the nonlinear linearising control law $(\mathbf{2 7}, \mathbf{3 4})$, which theoretically transforms the closed loop system into two parts. The first part consists of a cascade of $\rho$ integrators and the second is an unobservable subsystem of dimension $(n-\rho)$ ( $\rho$ is the relative order of the output, $n$ is the system order). With:

$w$ is the linearized system input

$L_{f} h$ is the Lie derivative of $h$ along $f$ which is given by

$$
L_{f} h(\underline{x})=\sum_{i=1}^{n} \frac{\partial h}{\partial x_{i}} f_{i}(\underline{x})
$$

$L_{g} h$ is the Lie derivative of $h$ along $g$

$\rho$ is the characteristic number associated to the output which is defined by $\rho=\min \left\{k \in N / L_{g} L_{f}^{\rho-1} \neq 0\right\}$

A simple calculation shows that the characteristic number is equal to three. With the new following co-ordinates:

$$
\left\{\begin{array}{l}
y=h \\
v=L_{f} h \\
\gamma=L_{f}^{2} h \\
p_{P}=p_{P}
\end{array}\right.
$$

These relations define a local diffeomorphism around an equilibrium state. In the new coordinates, the closed-loop system becomes

$$
\left\{\begin{array}{l}
\frac{d y}{d t}=v \\
\frac{d v}{d t}=a \\
\frac{d \gamma}{d t}=w=j_{c} \\
\frac{d p_{P}}{d t}=\frac{k r T_{s}}{V_{P}(y)}\left[\varphi\left(p_{P}\right)-\frac{S_{P}}{r T_{s}} p_{P} v+\psi\left(p_{P}, \operatorname{sgn}(U)\right) U\right]
\end{array}\right.
$$

In the single input output case, the linearising nonlinear control is given by:

$U=\frac{1}{L_{g} L_{f}^{\rho-1} h}\left(-L_{f}^{\rho} h+w\right)$

and here, it leads to the following control law: 


$$
U=\frac{1}{L_{g} L_{f}^{2} h}\left(-L_{f}^{3} h+w\right)
$$

where:

$$
\left\{\begin{aligned}
L_{g} L_{f}^{2} h & =\frac{S_{P}}{M} \frac{k r T_{s}}{V_{P}(y)} \psi\left(p_{P}, \operatorname{sgn}(U)\right)+\frac{S_{N}}{M} \frac{k r T_{s}}{V_{N}(y)} \psi\left(p_{N}, \operatorname{sgn}(-U)\right) \\
L_{f}^{3} h & =\frac{S_{P}}{M} \frac{k r T_{s}}{V_{P}(y)}\left[\varphi\left(p_{P}\right)-\frac{S_{P}}{r T_{s}} p_{P} v\right] \\
& -\frac{S_{N}}{M} \frac{k r T_{s}}{V_{N}(y)}\left[\varphi\left(p_{N}\right)+\frac{S_{N}}{r T_{s}} p_{N} v\right]
\end{aligned}\right.
$$

It is important to note that $L_{g} L_{f}^{2} h$ is always strictly positive. So $U$ has the same sign as $\left(-L_{f}^{3} h+w\right)$.

$w$ is by definition independent of $U$ and $L_{f}^{3} h$ too, according to (37). Consequently, the control law is not implicit (this remark explains the choice of the function $\varphi$ independent of $U$ in the mass flow rate expression (6) of section 3.2.2).

It can be noticed that on the contrary to the linear first feedback, this nonlinear feedback requires additionally the measurement of the two chamber pressures.

\section{Study of the residual dynamic}

The proposed control law leads to an unobservable subspace of dimension one. So the validity of the control law depends on the stability of the unobservable subsystem. The linear part of the closed loop system is well stabilised with an appropriate feedback. To prove the complete asymptotic stability of the control law, the stability of the internal dynamics will be studied. In this section, when the actuator stops (i.e. : $y=y_{\text {stop }}, v=$ $0, U=U_{\text {stop }}$ ), the asymptotic local stability of the equilibrium point of the internal dynamic is proved.

The differential equation of $p_{P}$ is in the form :

$$
\frac{d p_{P}}{d t}=\frac{k r T_{s}}{V_{P}\left(y_{\text {sop }}\right)}\left[\varphi\left(p_{P}\right)+\psi\left(p_{P}, \operatorname{sgn}\left(U_{\text {sop }}\right)\right) U_{\text {sop }}\right]
$$

Firstly assume that $U_{\text {stop }}>0$. Then this first order nonlinear equation has an only one equilibrium point $p_{P}^{e}$ because the two functions $\varphi(p)$ and $\psi(p)$ are decreasing monotonous (see figures 7 and 8 ) and $\psi(p)$ is always positive and $\varphi(p)$ has a zero. Then using the Lyapunov function
$V=\frac{1}{2}\left(p_{P}-p_{P}^{e}\right)^{2}$ the asymptotic stability of the equilibrium point $p_{P}^{e}$ is easily proved.

The same result may be obtain with $U_{\text {stop }}<0$.

With the same feedback as for linear tracking and the same boosting input ( $\mathrm{u}_{\text {boost }}$ ), the nonlinear control applied to the electropneumatic system may be written as:

$\begin{aligned} u= & \Gamma^{-1}\left(\frac{1}{L_{g} L_{f}^{2} h}\left(-L_{f}^{3} h+j_{d}-K_{y 2}\left(y_{d}-y\right)-K_{v 2}\left(v_{d}-v\right)-K_{a 2}\left(a_{d}-a\right)\right)\right)(39) \\ & +u_{\text {boost }}\end{aligned}$

The figure 19 shows the first nonlinear feedback.

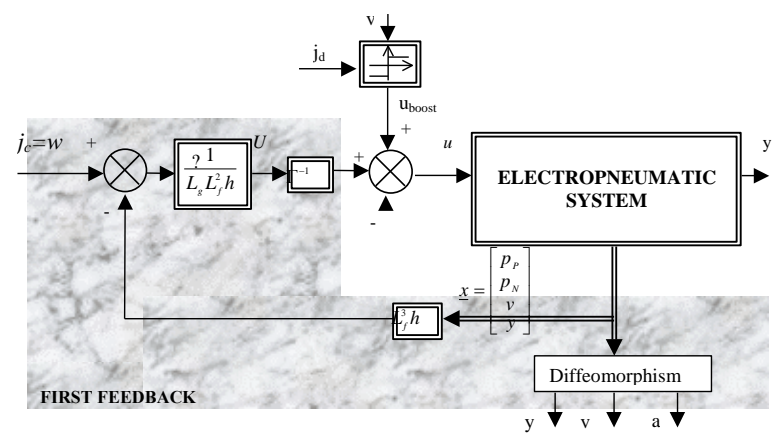

Fig. 19 Nonlinear first feedback for nonlinear tracking control.

\subsection{Comparison of experimental results}

After different tests, we noticed that to speak about repeatability, one hundred cycles are sufficient, because a Gaussian repartition of the results is obtained. All results are saved with a numerical recorder (Odyssey from Nicolet). The mean value, standard deviation $(\sigma)$, maximum and minimum values of position and velocity errors are calculated all along the trajectory.

An example of the obtained results is shown in figures 20 and 21 for the trajectory with constant velocity of figure $15 \mathrm{a}$ in the case of movement during rod out. The different curves correspond to a statistical analysis of linear and nonlinear tracking. The results give the reader a great deal of information during the piston trajectory and the performance in terms of repeatability are clearly pointed out. 

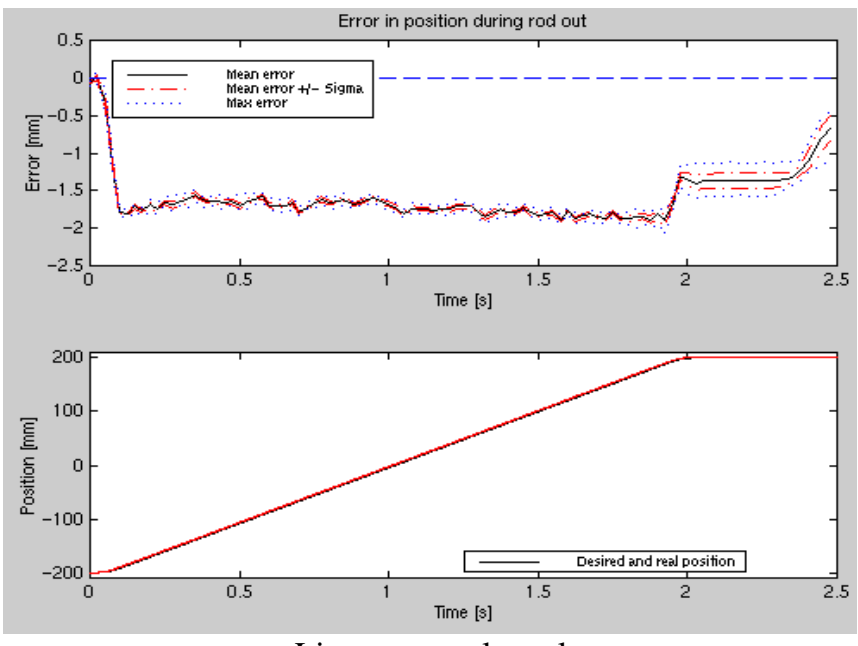

a Linear control results
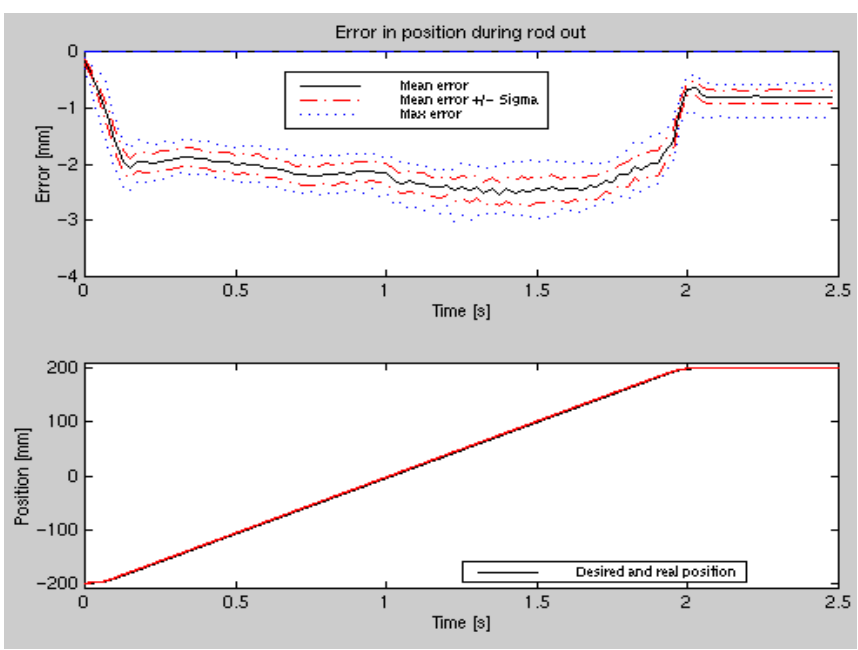

b Nonlinear control results

Fig.20 Error in position.

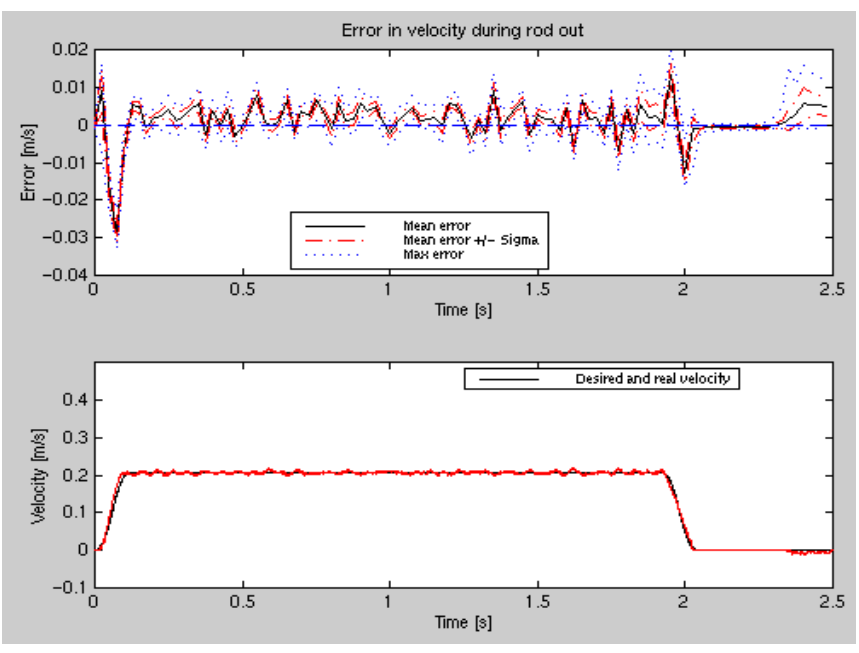

a Linear control results
Journal of SYSTEMS AND CONTROL ENGINEERING

Special Issue 'Controls in Fluid Power Systems' Error in velocity during rod out

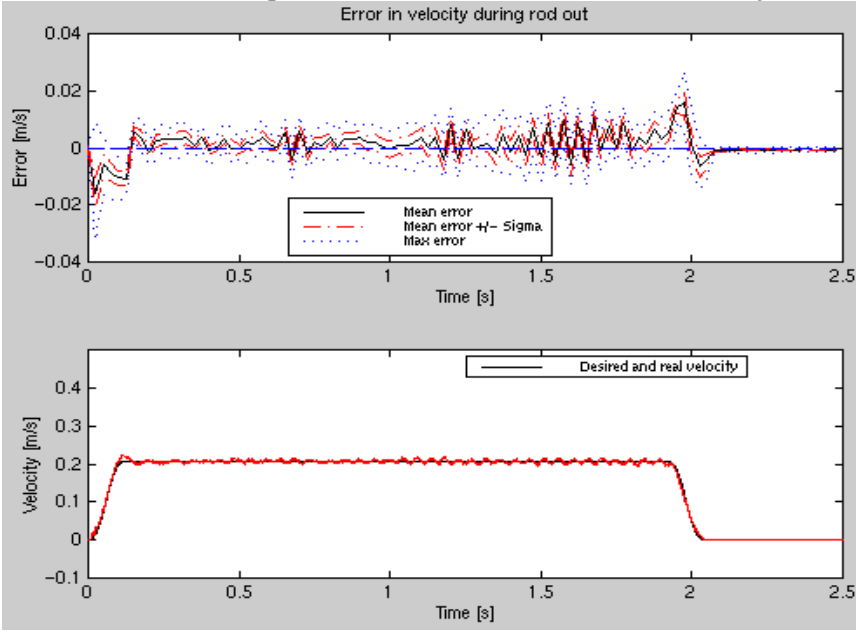

b Nonlinear control results

Fig.21 Error in velocity.

\section{Results analysis}

Firstly we have noticed that both control laws lead to good results with the two trajectories all along the cylinder stroke. The results are similar in steady state with the two control laws: the steady state error is about 0.20 millimetres.

A detailed study of all curves shows the improvement obtained with nonlinear control law during dynamic phases with constant velocity and constant acceleration or deceleration stages. An improvement of at least $25 \%$ can be seen in the maximum position and velocity error recorded with the nonlinear control law. During the constant velocity stage (trajectory 15a), the tracking position error is no more than 4 millimetres with the linear control law and lower than 3 millimetres with the nonlinear control law. These two numbers are respectively equal to 8 and 6 millimetres during constant acceleration or deceleration stages. The improvement due to nonlinear control law in terms of velocity tracking is even more appreciable. The maximum tracking velocity error for the first trajectory is about $0.07 \mathrm{~m} / \mathrm{s}$ with linear control law and $0.05 \mathrm{~m} / \mathrm{s}$ with nonlinear and respectively $0.04 \mathrm{~m} / \mathrm{s}$ and $0.02 \mathrm{~m} / \mathrm{s}$ with the second trajectory (figure 15b).

For industrial processes, the most important criterion is the repeatability of the results. That is why the table 4 resumes in term of repeatability the improvement due to the nonlinear control law. We recall that for a Gaussian distribution, 68.3\% of the results are included between the mean value 
\pm standard deviation. So, table 4 presents the study of the mean tracking position error obtained with the two control laws for the two different desired trajectories of figure 15 .

\begin{tabular}{|c|c|c|c|c|c|c|c|}
\hline & Type of trajectory & \multicolumn{3}{|c|}{ With constant velocity } & \multicolumn{3}{|c|}{ "With constant acceleration } \\
\hline & Control law & Linear & Nonlinear & \multirow[t]{2}{*}{ Improv. } & Linear & Nonlinear & \multirow[t]{2}{*}{ Improv. } \\
\hline Gaussian & $\max _{\forall t}(\sigma(t))[\mathrm{mm}]$ & 0.60 & 0.25 & & 0.05 & 0.10 & \\
\hline distribution & $\max _{\forall t}(\bar{\varepsilon}(t))[\mathrm{mm}]$ & 3.20 & 2.50 & $22 \%$ & 7.30 & 5.80 & $21 \%$ \\
\hline $68.3 \%$ & $\max _{\forall t}(\mid \bar{\varepsilon}(t) \pm \sigma(t)) \mid[\mathrm{mm}]$ & 3.80 & 2.75 & $28 \%$ & 7.35 & 5.90 & $20 \%$ \\
\hline $90,0 \%$ & $\max _{\forall t}(|\bar{\varepsilon}(t) \pm 1.64 \times \sigma(t)|)[\mathrm{mm}]$ & 4.18 & 2.91 & $30 \%$ & 7.38 & 5.96 & $19 \%$ \\
\hline $99,0 \%$ & $\max _{\forall t}(|\bar{\varepsilon}(t) \pm 2.58 \times \sigma(t)|)[\mathrm{mm}]$ & 4.75 & 3.15 & $34 \%$ & 7.43 & 6.06 & $18 \%$ \\
\hline
\end{tabular}

Table 4 Statistical comparisons between nonlinear and linear tracking control laws, in terms of position error.

For example the improvement in terms of position error of $30 \%$ in this table means that in $90 \%$ of cases, the tracking position error calculated as the mean value is less or equal to 4.18 millimetres throughout the cycle in case of the linear law and is less or equal to 2.91 millimetres with nonlinear control law: so the improvement is $30 \%$.

The improvement obtained with the use of nonlinear law is not very surprising since for the synthesis, the nonlinearities of the flow stage mass flow rate are taken into account by the approximation (6). On the contrary, the use of the tangent linearised model transforms the system in a triple integrator (as the reference model) only for one position.

For industrial applications, the complexity of nonlinear control will not be a problem in terms of the numerical implementation. Nevertheless, the nonlinear linearising control law needs two supplementary pressure sensors. Nowadays, however, this is not a financial difficulty. However it is important to note that the linear control is far easier and more rapid to synthesize. Thus, it can be a solution in particular applications where less precision is required.

\section{CONCLUSIONS}

This paper has presented the synthesis of an electropneumatic nonlinear model for positioning system. Appropriate and justified hypotheses lead to a linear reduced model.
The greatest problem for this kind of system concerns modelling the nonlinearities of the servodistributor mass flow rate. For the first time a mathematical approximation of the mass flow rate coming from experimental characterisation has been presented and validated. This leads to a nonlinear affine model, which can be used for nonlinear control synthesis.

State feedback controls with fixed and scheduling gains have been studied and the improvements obtained with the scheduling gains in terms of repeatability and response time are quantified for a point to point displacement for different positions along the cylinder stroke.

Using tracking control for two kinds of trajectories, a nonlinear control law based on input-output linearisation leads to better results, especially in terms of repeatability, than a linear control law established with the tangent linearised model.

This quantified and structured comparison should be continued for other control laws, with an evolved benchmarking (sticking and restarting phenomenon (26), robustness to mass variation or to force perturbation, stiffness of system...) and the same device. What results will be obtained for an adaptive algorithm, a sliding control, a $\mathrm{H}_{\infty}$ robust control, a fuzzy control, a neural control...?

\section{ACKNOWLEDGEMENTS}

For the two years 1997 and 1998, this work has been supported by a grant from the PRC-GDR 
Automatic Control of the French National Centre for Scientific Research, CNRS.

\section{REFERENCES}

1 EDGE, K.A., The control of fluid power systems - responding to the challenge. Journal of Systems and Control Engineering, 1997, Vol 211, N¹2, p. 91-110.

2 SHEARER, J.L., Study of pneumatic processes in the continuous control of motion with compressed air. Parts I and II. Trans. Am. Soc. Mech. Eng. 1956, Vol. 78, p. 233-249.

3 BURROWS, C.R. Fluid Power Servomechanisms. London : Van Nostrand Reinhold Company, 1972. 237 p.

4 MORGAN, G., HÜBL, W., Positionieren mit kleinrechnern von Pneumatikzylindern . In: 6th Aachener fluid techniches kolloquium, Aachen, 1984, p. 121-157

5 EDGE, K.A, FIGEREDO, K.R.A., An adaptively controlled electrohydraulic servo-mechanism: Part 1: Adaptive controller design - Part 2: Implementation. In: Proc. Instn. Mech. Engrs. Part B, 1987, Vol 201, N³n p 175-180 and p. 181-189

6 NORISTUGU, T., WADA, T., YANOSAKA, M., Adaptive control of electropneumatic servo system. In: 2nd Int. Symp. On Fluid -Control, Measurement, Mechanics and flow visualisation. Sheffield, England, 1988, p. 285-289.

7 VAUGHAN, N. D., GAMBLE, J. B., Sliding mode control of a proportional solenoid valve. Fluidpower Systems Modelling and Control. Burrows C. R. and Edge K. A. Eds. Taunton : Research Studies Press, 1992, p. 95-107.

8 BOURI, M., THOMASSET, D., SCAVARDA, S., Integral sliding mode controller of a rotational servodrive. Third Japan Hydraulics Pneumatics Society, Tokyo, November 1996. p 145-150

9 SURGENOR, B.W., VAUGHAN N.D., UEBING, M., Continuous sliding mode control of a pneumatic positioning system. $8^{\text {th }}$ Bath Int. Fluidpower Workshop, UK., Sept. 1995.

10 PICHE, R., POHJOLAINEN, S., VIRVAlO, T., Design of robust controllers for position servos using $H$-infinity theory. Proc. Instn Mech Engrs, Part I, 1991, 205(I4), p. 299-306.

11 KLEIN, A. BACK, W., An intelligent optimisation of a state loop controller with fuzzy-set-logic. In Circuit Component and System Design, Proceedings of Fifth Bath International Fluid Power Workshop (Eds Burrows and Edge), 1995, pp 381-399.

12 LIU, P., DRANSFIELD, P., Intelligent control of air servodrives using neural networks. Proc. of Second Japan Hydraulics Pneumatics Society, Tokyo, 1993, p. 381-399.

13 BELGHARBI, M., BRUN, X., SCAVARDA, S.,SESMAT, S., THOMASSET, D., Dispositifs expérimentaux .Rapport 1, $\mathrm{PRC/GDR}$ "Modélisation et commande des systèmes à fluide sous pression". Labo. Auto. Industr, INSA-Lyon, 1997, 60 p.

14 BELGHARBI, M., BRUN, X., SCAVARDA, S., SESMAT, S., THOMASSET, D. Eléments de modélisation en électropneumatique - Modèles de différents systèmes électropneumatiques. Rapport 2, PRC/GDR "Modélisation et commande des systèmes à fluide sous pression". Labo. Auto. Industr, INSA-Lyon, 1997, $80 \mathrm{p}$.

15 SESMAT, S. Modélisation, Simulation et Commande d'une Servovalve Electropneumatique. Thèse: Sci.: Institut National des Sciences Appliquées de Lyon, 1996, 307 p.
16 SESMAT, S., SCAVARDA, S. Static characteristics of a three way servovalve. 12th Aachen Conf. on Fluid Power Technology, Aachen, Deutsch., March 12-13,1996, p. 643-652.

17 BOUHAL, A. Contribution à la commande linéaire et non linéaire adaptative des systèmes électropneumatiques. Thèse: Sci.: INSA de Lyon, 1994. 203 p.

18 ARAKI, K. Effects of valve congiguration on a pneumatic servo. In: 6th International Fluid Power Symposium, Cambridge, 1981, Paper F2, p. 271-290.

19 MO, J. P. T. Analysis of compressed air flow through a spool valve. In: Proceedings of the Institution of Mechanical Engineers, 1989, vol. 203, n 2, p. 121-131.

20 RICHARD, E., SCAVARDA, S., Nonlinear control of pneumatic servodrive. Proc. Second Bath Int. Fluid Power Workshop - 21-22 September 1989 Bath (U.K.), p. 59-75.

21 Mc CLOY, D., MARTIN, H.R. Control of fluid power : analysis and design., Ellis Horwood, 1980. 510 p.

22 Norme ISO 6358 Transmissions pneumatiques - Eléments traversés par un fluide compressible - Détermination des caractéristiques de débit. $1989,15 \mathrm{p}$

23 BELGHARBI, M., THOMASSET, D., SCAVARDA, S., SESMAT, S., Analytical model of the flow stage of $a$ pneumatic servo-distributor for simulation and nonlinear control. to appear in the Sixth Scandinavian Int. Conference on Fluid Power, SICFP'99, Tampere, Finland, 1999, p 847-860.

24 SHEARER, J.L. Study of pneumatic processes in the continuous control of motion with compressed air. Parts I and II. Trans. Am. Soc. Mech. Eng. 1956, Vol. 78, p.233-249.

25 ANDERSEN, B.W. The analysis and design of pneumatic systems. New-York: John Wiley and Sons, 1967. 302p.

26 BRUN, X., SESMAT, S., SCAVARDA, S., THOMASSET, D. Simulation and experimental study of the partial equilibrium of an electropneumatic positioning system, cause of the sticking and restarting phenomenon in $4^{\text {th }}$ Japan Hydraulics Pneumatics Society, Tokyo, 15-17 November 1999.

27 ISIDORI, A. Nonlinear control systems. New York : Springer Verlag, $2^{\text {nd }}$ edition, $1989.479 \mathrm{p}$.

28 SESMAT, S., SCAVARDA, S. Study of the behaviour of an electropneumatic positioning system near the equilibrium state Int. Fluid Kolloq. In Aachen, Aachen, 17-18 Marz 1998, vol. 2, pp 321-334.

29 KELLAL, A., SCAVARDA, S., FONTAINE, J.G. Electropneumatic servodrive for a robot. Proceedings of the 16th ISIR - International Symposium on Industrial Robots, Brussels, Belgium, 29 Sept. - 2 Oct, 1986, p. 117-128

30 SESMAT,S., SCAVARDA, S., LIN-SHI, X., Verification of electropneumatic servovalve size using non-linear control theory applied to cylinder position tracking. $4^{\text {th }}$ Scandinavian Int Conf on Fluid Power, Sept 26-29, 1995, Tampere, Finland.

31 SESMAT, S., SCAVARDA, S., THOMASSET, D. Comparison of three tracking control laws for an electropneumatic positioning system. Congresso Int. della Trasmissione di Potenza '97, Automazione e progettazione, Sessione Pneumatica, Assago (MI), Italia, 1997, p. 611-622

32 RICHARD, E., SCAVARDA, S. Comparison between Linear and Nonlinear control of an eletropneumatic servodrive. Journal of Dynamic Systems, Measurement, and Control, June 1996, Vol. 118, p. 245-252. 